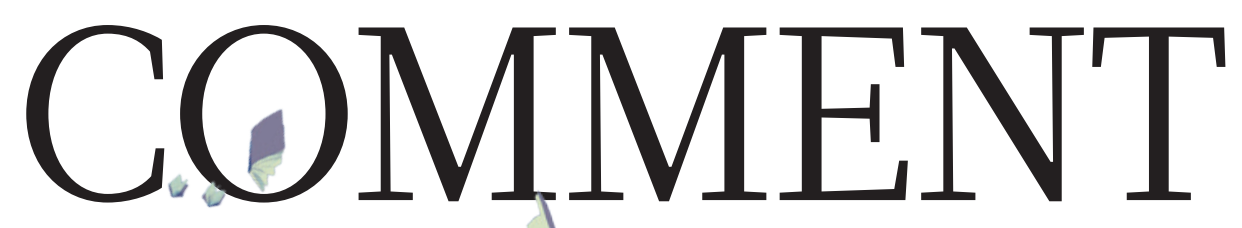

SUSTAINABILITY How to resolve the clash between food and energy for land? p.526
SUMMER BOOKS Regular reviewers pick their holiday reads $\mathbf{p . 5 2 8}$
ENGAGEMENT Why ten US

seminaries have piloted a science curriculum p.531
OBITUARY Irwin Rose, who worked out the role of ubiquitin, remembered $\mathbf{p . 5 3 2}$

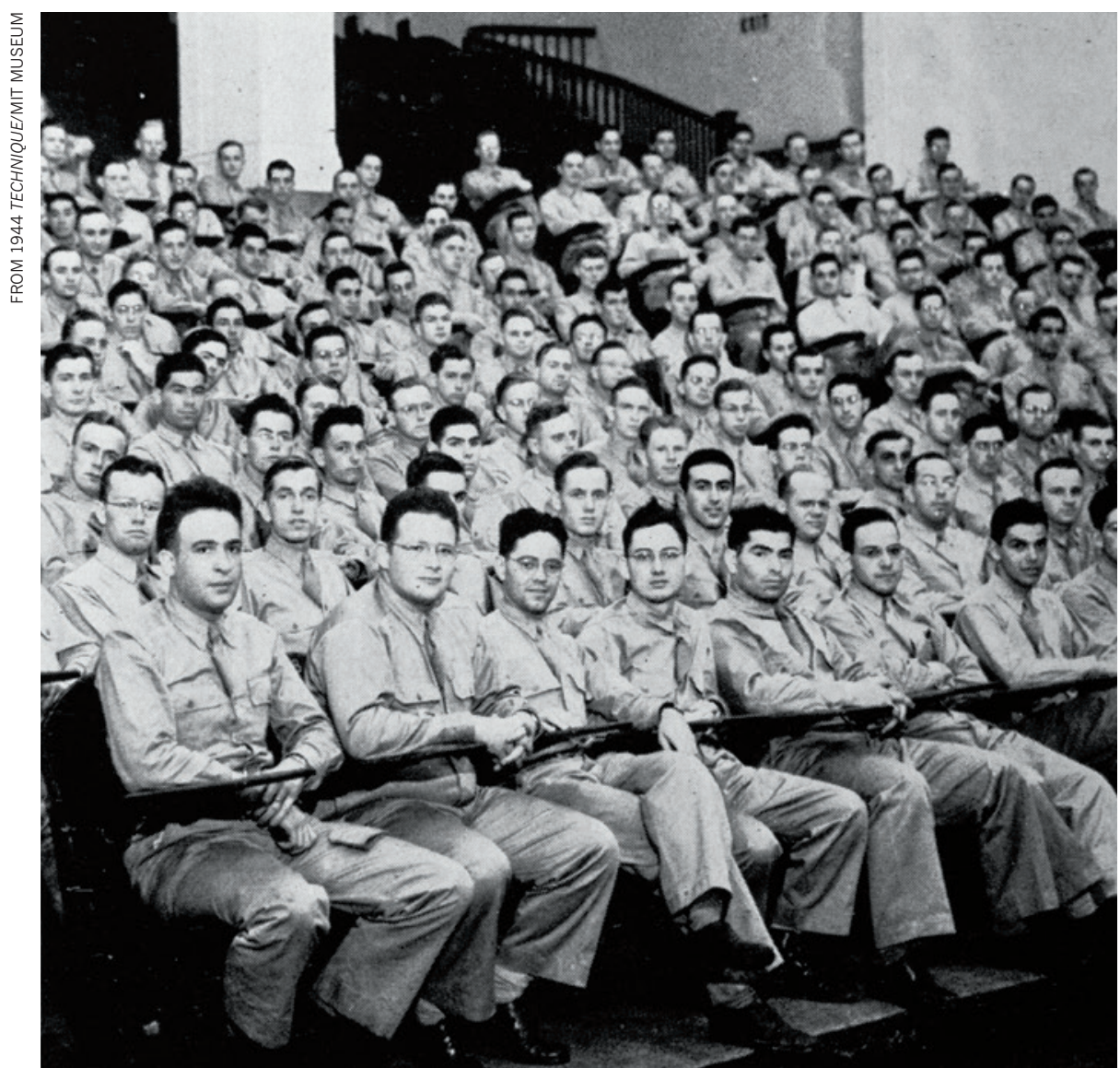

Members of the US Army attend a physics lecture at the Massachusetts Institute of Technology in 1944.

\section{From blackboards to bombs}

S eventy years ago, on 6 and 9 August 1945, mushroom clouds erupted skyward above the smouldering cities of Hiroshima and Nagasaki, Japan. For the first time - and, so far, the only time nuclear weapons had been used in combat. Hundreds of thousands of people perished.
Many died from the immediate force and fire of the blasts; others succumbed later to acute radiation sickness. Days after the bombs were dropped, Japan surrendered and the Second World War lumbered to a close.

The Second World War marked an unprecedented mobilization of scientists and engineers, and a turning point in the relationship between research and the state. By the end of the war, the nuclear weapons project, code-named the Manhattan Engineer District, absorbed thousands of researchers and billions of dollars. It sprawled across 30 facilities throughout the United States and Canada, with British teams working alongside Americans and Canadians. Allied efforts on radar swelled to comparable scale.

The drama with which the war ended the detonation of nuclear weapons over cities - cemented the association of the Second World War as 'the physicists' war.' Yet the term had been coined long before August 1945 , and originally it had nothing to do with bombs or radar. Rather, the physicists' war had referred to an urgent, ambitious training mission: to teach elementary physics to as many enlisted men as possible.

Both views of how scientists could serve their nations - the quotidian and the cataclysmic - have shaped scientific research and higher education to this day.

\section{CATCHY PHRASE}

In late November 1941, just weeks before the United States entered the global conflict, James Conant explained in a newsletter of the American Chemical Society that "this is a physicist's war rather than a chemist's" . Conant was well-placed to know: he was president of Harvard University in Cambridge, Massachusetts, chair of the US National Defense Research Committee (NDRC), and a veteran of earlier chemicalweapons projects.

The phrase had instant appeal; others quickly began to quote it. In 1949, for example, Life magazine profiled ${ }^{2}$ physicist J. Robert Oppenheimer, who had served as scientific director of the wartime Los Alamos laboratory in New Mexico, a central node of the Manhattan Project. Referring to massive military projects such as the bomb and radar, the reporter invoked "the popular notion" that the Second World War had been "a physicists" war".

By that time, the meaning of Conant's formulation seemed self-evident. The First World War, with its notorious battlefield uses of poison gases such as phosgene and chlorine, had been dubbed the chemists' war. The bomb and radar presented a logical counterpoint. 
> But Conant had very different ideas when he introduced the now-famous phrase. It was hardly clear in November 1941 that either the bomb or radar would change the tide of the war. The Radiation Laboratory, or 'Rad Lab', at the Massachusetts Institute of Technology (MIT) in Cambridge - which served as headquarters for the Allied effort to improve radar - was just one year old. A prototype radar system had recently been rejected by a US Army review board, and NDRC funding had nearly been revoked. The Manhattan Project did not exist yet. Los Alamos still housed a private boys' school. A year and a half would elapse before the mudcaked ranch houses were requisitioned for the top-secret laboratory.

There is also the matter of secrecy. Conant oversaw both radar development and the nascent nuclear-weapons programme; information about each was strictly classified. An experienced, high-ranking government adviser such as Conant surely did not intend to disclose some of the nation's most closely guarded secrets.

And there is the nature of the radar and bomb projects themselves. Although each was directed by physicists, they teemed with specialists of all stripes. By the end of the war, physicists were a minority - only about onefifth - of the Rad Lab staff. At Los Alamos, the wartime organization chart displayed the groups - metallurgy, chemistry, ballistics, ordnance and electrical engineering, as well as physics - arranged in a circle, connected by spindly links. No group appeared on top directing the others. Researchers at both the Rad Lab and Los Alamos forged new kinds of hybrid, interdisciplinary spaces during the war. Neither could be categorized simply as a physics laboratory $^{3}$ (see D. Kaiser Nature 505, 153-155; 2014).

So what was Conant talking about?

\section{CLASSROOM MOBILIZATION}

To most scientists and policy-makers in the early 1940s, the physicists' war referred to a massive educational mission.

In January 1942, the director of the American Institute of Physics (AIP), Henry Barton, citing Conant, began issuing bulletins entitled 'A Physicist's War'. Barton reasoned that "the conditions under which physicists can render services to their country are changing so rapidly" that department chairs and heads of laboratories needed some means of keeping abreast of evolving policies and priorities. The monthly bulletins focused on two main topics: how to secure draft deferments for physics students and personnel, and how academic departments could meet the sudden demand for more physics instruction.

Modern warfare, it seemed, required rudimentary knowledge of optics and acoustics, radio and circuits. Before the war, the US Army and Navy had trained technical specialists from within their own ranks, at their own facilities. The sudden entry of the United States into the war required new tactics. University physicists, consulting with army and navy officials, reported early in the conflict that enrolments in highschool physics classes would need to jump by $250 \%$. Their goal: half of all high-school boys in the country should spend at least one class per day focusing on electricity, circuits and radio ${ }^{4}$.

The navy and the army also called for massive numbers of military personnel to receive basic training in physics at established colleges and universities. Draft curricula circulated between military officials and the AIP. The army, for example, wanted the new courses to emphasize how to measure lengths, angles, air temperature, barometric pressure, relative humidity, electric current and voltage. Lessons in geometrical optics would emphasize applications to battlefield scopes; lessons in acoustics would drop examples from music in favour of depth sounding and sound ranging.

So acute was the need to teach elementary physics that a special committee recommended that university departments discontinue courses in atomic and nuclear physics for the duration of the war so as to devote more teaching resources to truly "essential" material".

Between December 1942 and August 1945, a quarter of a million students passed through elementary physics classes at
US colleges and universities. Staffing the inflated classrooms required military-style planning and logistics. Barton's bulletins warned that any universities found to be hoarding valuable physics teachers - much less poaching them from other schools would be subject to "severe criticism". Barton developed a complicated formula for what he termed the acceptable "ratio of genuine to 'ersatz' teachers of physics" in any given institution. Physics teachers became a rationed commodity: like rubber, gasoline and sugar, they were in critically short supply.

Draft policies quickly followed. The US government created a National Committee on Physicists in December 1942 - the first of its kind for any academic speciality — to advise local draft boards on the need for teaching-related deferments. Soon the phrase the physicists' war echoed throughout newspapers, popular magazines and even congressional testimony. Use of the phrase peaked in 1943, long before there was much to report (classified or otherwise) about the Manhattan Project (see 'Branding exercise').

\section{SECRECY AND THE SMYTH REPORT}

Use of the phrase the physicists' war rebounded every decade or so, usually around an anniversary of the bombings of Hiroshima and Nagasaki. The highest postwar peak accompanied the publication of Richard Rhodes's Pulitzer-prizewinning book, The Making of the Atomic Bomb, in 1986. By then, Conant's phrase had long since been linked with classified military projects rather than classroom instruction.

The transition began almost as soon as the bombs were dropped on Japan. General Leslie Groves, who was overseeing the

\section{BRANDING EXERCISE}

The phrase 'the physicists' war', coined to call for mass education as the United States entered the Second World War, took on a new life after August 1945.

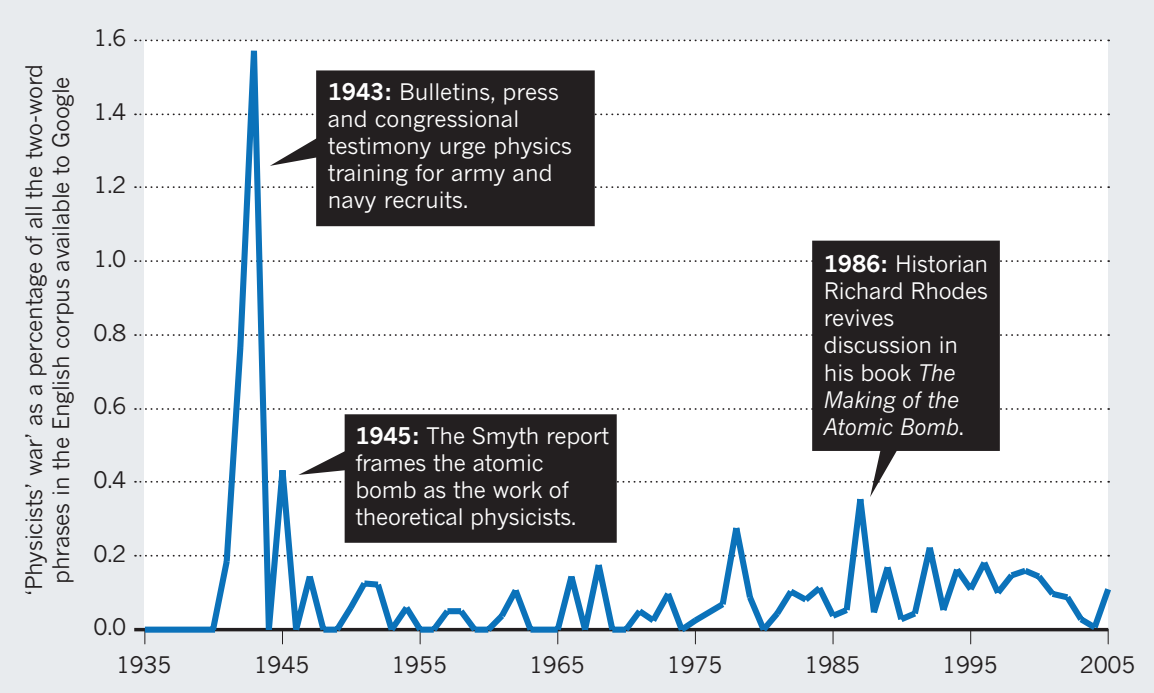




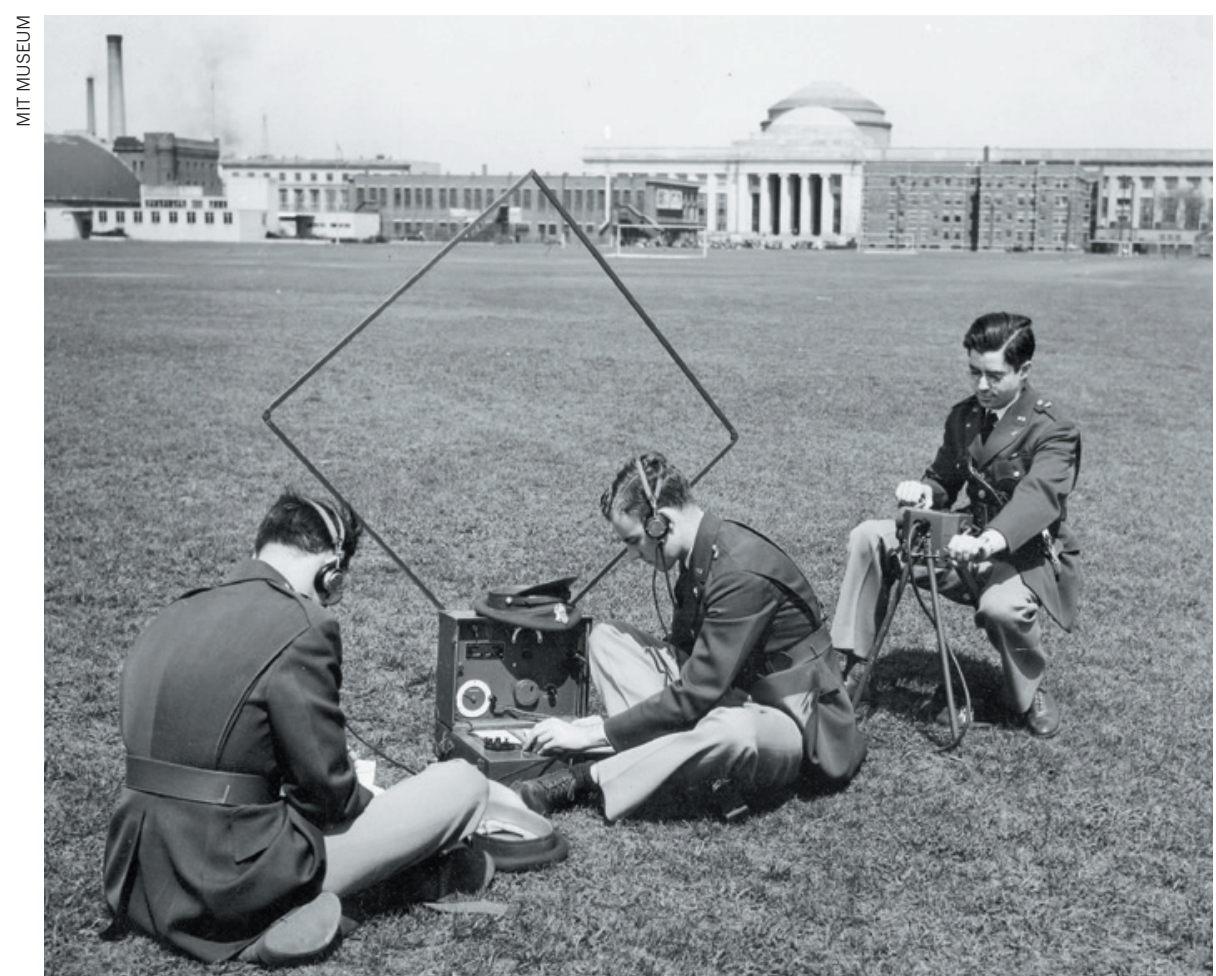

Reserve Officer Training Corps students use a portable radio as part of their training at MIT (about 1944).

Manhattan Project, anticipated that the government would need to have some information ready to release about the top-secret nuclear-weapons project — pre-cleared and available for wide distribution - in case the bombs were ever used. Early in the project, he tapped nuclear physicist Henry DeWolf Smyth at Princeton University in New Jersey to spend the war visiting each Manhattan Project site, compiling a technical report that would be suitable for public dissemination.

On the evening of 11 August 1945, just two days after the bombing of Nagasaki, the US government released Smyth's 200-page document under the ponderous title, 'A General Account of Methods of Using Atomic Energy for Military Purposes under the Auspices of the United States Government, 1940-1945'. Quickly dubbed 'the Smyth report', copies flew off the shelves. The original Government Printing Office edition ran out so quickly that Princeton University Press published its own edition late in 1945, under the more manageable title, Atomic Energy for Military Purposes, which sold more than 100,000 copies in a year.

Security considerations dominated what Smyth could include. Only information that was already widely known to working scientists and engineers, or which had "no real bearing on the production of atomic bombs", was deemed fit for release. Little of the messy combination of chemistry, metallurgy, engineering or industrial-scale manufacturing met these criteria; these aspects of the huge project, crucial to the actual design and production of nuclear weapons, remained closely guarded ${ }^{6}$.

So Smyth focused on ideas from physics, pushing theoretical physics, in particular, to the forefront. Ironically, most people read in Smyth's report the lesson that physicists had built the bomb (and, by implication, had won the war) ${ }^{6,7}$. Later reports, such as 'Essential Information on Atomic Energy', issued in 1946 by the new Special Committee on Atomic Energy of the US Senate, borrowed liberally from the Smyth report, depicting nuclear weapons as the latest in a series of developments in theoretical physics. A chronological table at the end extended the narrative as far back as $400 \mathrm{BC}$ to the ancient Greek atomists. There was little mention of the Berlin chemistry laboratory in which nuclear fission had been discovered late in 1939, much less the work of chemical engineers at US company DuPont, who scaled up plutonium-producing nuclear reactors during the war.

\section{LONG SHADOW}

The change in referent for the physicists' war - from blackboards to bombs had serious implications. After the war, physicists in the United States bore the largest brunt of any academic group during the 'red scare' of the 1950s, promoted by Senator Joseph McCarthy. The House Un-American Activities Committee held 27 hearings on allegations against physicists, twice the number for any other scholarly discipline. If nuclear weapons had been made by physicists, the reasoning went, then physicists must have special access to the 'atomic secrets' with which such bombs could be made. Thus the loyalties of this group required the closest scrutiny ${ }^{8}$.

Meanwhile, the two meanings of the physicists' war blurred together as the cold war intensified. More and more universities became contracting sites for military and defence agencies, continuing the model that Conant and others had forged during the war. Physicists' research budgets ballooned, and enrolments grew faster than in any other field, doubling every few years.

More physicists were trained in the United States, United Kingdom and Soviet Union in the quarter-century after the war than had been trained throughout all of previous history. Yet the aims of the training shifted in the 1950s and 1960s. Rather than teaching soldiers some elementary physics to prepare them for the battlefield, US officials spoke of creating a 'standing army' of physicists, who could work on nuclearweapons projects without delay should the cold war ever turn hot ${ }^{9}$.

Three decades after 1945, years into the slog of the Vietnam War, many critics grew uneasy with the close association between physics and war. Campus protesters demanded that the defence department get out of the higher-education business. At universities across the United States, physicists' laboratories became frequent targets for sitins and even Molotov cocktails ${ }^{10}$.

After the protesters dispersed and the tear gas lifted, several things had become clear. 'The physicists' war' had massively altered the structure of the US university system, the organization of scientific research, and the relationship between national defence and higher education.

David Kaiser is professor of physics and of the history of science at the Massachusetts Institute of Technology, Cambridge, Massachusetts, USA. He is author of How the Hippies Saved Physics: Science, Counterculture, and the Quantum Revival. e-mail:dikaiser@mit.edu

1. Conant, J. B. Chem. Eng. News 19, 1237-1238 (1941).

2. Barnett, L. 'J. Robert Oppenheimer' Life 120-138 (10 October 1949).

3. Galison, P. Image and Logic: A Material Culture of Microphysics (Univ. Chicago Press, 1997)

4. Havighurst, R. J. \& Lark-Horovitz, K. Am. J. Phys. 11, 103-108 (1943).

5. Cope, T. D. et al. Am. J. Phys. 10, 266-268 (1942)

6. Schwartz, R. P. The Making of the History of the Atomic Bomb: The Smyth Report and the Historiography of the Manhattan Project PhD thesis, Princeton Univ. (2008).

7. Gordin, M. Five Days in August: How World War II Became a Nuclear War (Princeton Univ. Press, 2007).

8. Kaiser, D. Representations 90, 28-60 (2005).

9. Kaiser, D. Hist. Stud. Phys. Sci. 33, 131-159 (2002).

10. Moore, K. Disrupting Science: Social Movements, American Scientists, and the Politics of the Military, 1945-1975 (Princeton Univ. Press, 2008). 